\title{
Prevalence of Bacterial Vaginosis and Its Association with Risk Factors among Nonpregnant Women: A Hospital Based Study
}

\author{
Eliza Ranjit $\mathbb{D}^{1},{ }^{1}$ Bijendra Raj Raghubanshi, ${ }^{2}$ Smrity Maskey $\mathbb{D}^{\circ},{ }^{3}$ and Pramila Parajuli ${ }^{1}$ \\ ${ }^{1}$ Department of Microbiology, St. Xavier's College, Maitighar, Kathmandu, Nepal \\ ${ }^{2}$ Department of Microbiology, KISTMCTH, Lalitpur, Kathmandu, Nepal \\ ${ }^{3}$ Department of Gynaecology/Obstetrics, KISTMCTH, Lalitpur, Kathmandu, Nepal \\ Correspondence should be addressed to Eliza Ranjit; eleez.ranjit@gmail.com
}

Received 20 October 2017; Revised 10 January 2018; Accepted 31 January 2018; Published 5 March 2018

Academic Editor: Todd R. Callaway

Copyright (C) 2018 Eliza Ranjit et al. This is an open access article distributed under the Creative Commons Attribution License, which permits unrestricted use, distribution, and reproduction in any medium, provided the original work is properly cited.

\begin{abstract}
Bacterial vaginosis (BV) is an ecological imbalance of the vaginal microbiota affecting mostly women of reproductive age group. This study was carried out among 160 nonpregnant women registered at the Outpatient Department of Gynaecology/Obstetrics of KIST Medical College Teaching Hospital, Imadol, Lalitpur, Nepal, from November 2014 to May 2015. The aim of the study was to assess the association of the risk factors with BV and analyze the type of bacteria associated with BV. Nugent's scoring method was used for diagnosis of BV in this study. The overall prevalence of BV was $24.4 \%$ among symptomatic patients. Douching was statistically related to $\mathrm{BV}(P=0.015)$. Also, BV was significantly associated with consistency $(P=0.0001)$, odor $(P=0.02)$, and amount of abnormal vaginal discharge $(P=0.09)$. Contraceptives users on anatomical sites were found more prone to $\mathrm{BV}$ than those who did not use contraceptives on anatomical sites. Pseudomonas spp., Escherichia coli, Acinetobacter spp., Proteus spp., Klebsiella spp., Neisseria gonorrhoeae, Enterobacter spp., Citrobacter spp., Staphylococcus aureus, Coagulase-Negative Staphylococci (CoNS), and Streptococcus agalactiae were associated with BV and out of those Lactobacillus spp. was the predominant organism. The higher prevalence of BV among symptomatic patients indicates interventions should be applied to reduce the incidence of stillbirth, abortion, and sterility.
\end{abstract}

\section{Background}

Vaginitis is an inflammation of the vagina, usually characterized by any of the following: vaginal discharge containing many white blood cells (WBCs), vulvar itching, vulvar irritation, vaginal odor, vaginal erythema, dyspareunia, and dysuria $[1,2]$. The three most common causes of vulvovaginitis are bacterial vaginosis (BV), being the most prevalent one, followed by candidiasis and trichomoniasis [3]. BV is a common vaginal infection that occurs mostly in women of child-bearing age [4].

$\mathrm{BV}$ is a clinical condition characterized by a thin, gray/offwhite, homogenous, malodorous adherent vaginal discharge which is more noticeable after intercourse and menses, having $\mathrm{pH}>4.5$. Fishy odor is noticed on addition of $10 \%$ potassium hydroxide to the vaginal fluid (whiff test), and the presence of clue cells, a few or no lactobacilli, and small number $(<1 / \mathrm{hpf})$ of polymorphonuclear leucocytes (PMNs) are also the characteristic features of BV [5].

Many cases of BV remain asymptomatic or present with only malodorous vaginal discharge with no inflammatory complaints [6]; thus BV is therefore referred to as "vaginosis" and not "vaginitis" [7].

Lactic acid produced by the normal flora, Lactobacillus through hydrogen peroxide $\left(\mathrm{H}_{2} \mathrm{O}_{2}\right)$ production, is attributed to the acidic milieu of the vagina. This provides a local defense mechanism by inhibiting the growth of other organisms. Change in the normal vaginal flora causes change in $\mathrm{pH}$ simultaneously, which allows a variety of anaerobes and facultative bacteria to overgrow and cause chronic infection as well as abnormal vaginal discharge $[5,8]$. Lactobacilli also produce antimicrobial substances like lactic acid, $\mathrm{H}_{2} \mathrm{O}_{2}$, and bacteriocin to promote a healthy ecosystem in the vagina thereby suppressing the growth of pathogens $[8,9]$. 
Besides Lactobacillus spp., other bacteria are also frequently found in the vaginal microbiota of healthy women. The organism found are Gram positive cocci and Gram negative rods, namely, Streptococcus spp., Staphylococcus spp., and members of Enterobacteriaceae, mostly E. coli in addition to other anaerobic species e.g., Bacteroides spp., Bifidobacterium spp., Propionibacterium, Fusobacterium spp., Peptococcus spp., Prevotella spp., Veillonella spp., Peptostreptococcus spp., Atopobium vaginae, Gardnerella vaginalis, Ureaplasma urealiticum, Mycoplasma hominis, and Mobiluncus [10, 11]. When the population level of lactobacilli decreases below a critical level, these opportunistic bacteria may overgrow becoming the dominant species in the environment [12].

In pregnancy, vaginal infections can be associated with drastic complications both to the mother and the neonate [13], leading to gynaecologic and obstetric complications [12]. BV also increases the risk of acquiring Human Immunodeficiency Virus (HIV) and Sexually Transmitted Diseases (STDs). BV may be considered as Sexually Enhanced Disease (SED) rather than STDs, in which the frequency of intercourse plays a key role [14]. Hence, emphasis to explore primary preventive strategies needs to be given more priority.

Preventive strategies target the risk factors or behaviors for a disease. Studies suggest that BV is associated with a number of risk factors and behaviors, including age, marital status, employment status, occupation, recent antibiotic use, decreased estrogen production of the host, douching, sexual activity, lower age of first intercourse, more frequent episodes of receptive oral sex, spermicide use, STDs, working as a sex worker, smoking, alcohol intake, stress, contraceptives used, frequency of vaginal intercourse, and race/ethnicity $[15,16]$. A number of observational studies have reported that women using hormonal contraceptives have a reduced risk of recurrence to BV [17].

In particular, among the most prominent risk factors, sexual behavior and vaginal douching are modifiable risk factors [14]. However, few studies have determined the prevalence of $\mathrm{BV}$ and associated risk factors among women in Nepal. Therefore, this study was undertaken to assess the association of the risk factors with BV and analyze the type of bacteria associated with BV.

\section{Methods}

2.1. Study Design. A descriptive cross-sectional study was conducted among 160 nonpregnant women, attending KIST Medical College Teaching Hospital over a period of six months from November 2014 to May 2015.

2.2. Ethical Approval. Ethical statement was approved by the ethical committee of KIST hospital and a verbal consent of each of the patient was obtained. Questionnaires were used to collect sociodemographic, behavioral characteristics and medical, reproductive, and sexual history information.

2.3. Sample Collection and Processing. A nonlubricated speculum was inserted into the vagina to collect discharge and a physical examination of the discharge was performed

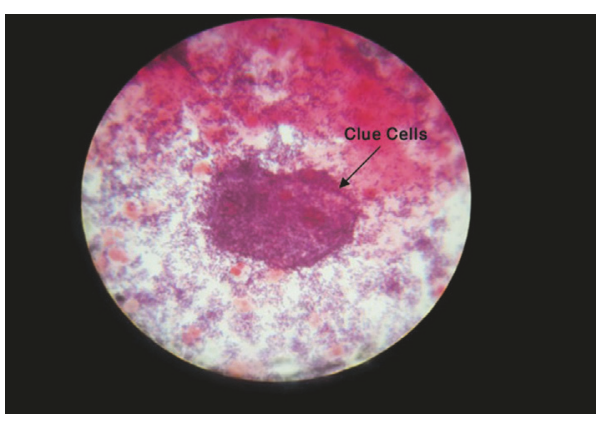

FIGURE 1: Clue cells on Gram-stained smear.

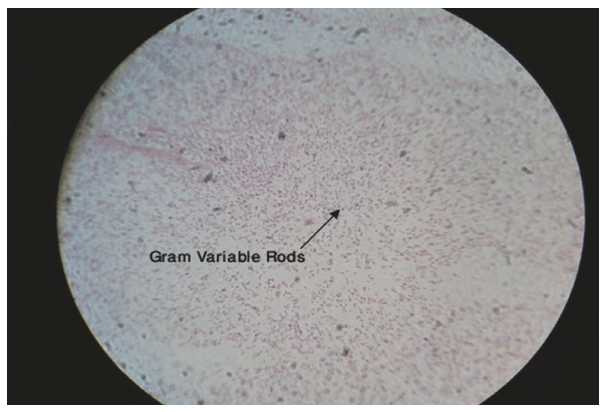

FIGURE 2: Gram-stained vaginal smears with Gram variable rods.

to observe its form, color, consistency, and odor. Then, two vaginal samples were taken with sterile cotton-tipped swabs from the lateral and posterior vaginal fornix.

One of the swabs was transported in sterile capped test tube to the Microbiology Laboratory for aerobic and anaerobic cultures in MacConkey agar, Blood agar, and Chocolate agar for identification of bacterial isolates. The former two agars were inoculated aerobically at $37^{\circ} \mathrm{C}$ for 24 hours and later anaerobically at $37^{\circ} \mathrm{C}$ in candle jar for 24 hours. Another swab was used for making a smear for Gram staining (Figures 1, 2, and 3) and direct wet mount microscopy. The Gram-stained slides were examined under oil immersion objective (1000x magnification). Then, the etiological agent and normal flora on the Gram-stained smear were counted and were scored according to the standardized Nugent's scoring method [18]. (Table 1).

The wet mount was performed to view the presence of motile oval flagellated protozoa, Trichomonas vaginalis, clue cells, and white blood cells. For yeasts, Gram staining and germ tube test was done. Candida albicans was identified by its ability to produce germ-tubes when incubated in serum for 2 hours at $37^{\circ} \mathrm{C}$.

2.4. Statistical Analyses. A descriptive analysis was performed to calculate prevalence of $\mathrm{BV}$ and microorganisms. Chi square values were calculated at 5\% $(\alpha=0.05)$ level of significance using the Statistical Package for Social Sciences (SPSS-16). 
TABLE 1: Scoring of bacterial morphotype on Gram-stained smear.

(a)

\begin{tabular}{lcccccc}
\hline Lactobacilli & Score & Gardnerella, Bacteroides & Score & Curved gram negative bacilli & Score & Sum $={ }^{*} \mathrm{~N}-$ score \\
\hline 30 or $>$ & 0 & 0 & 0 & 0 & 0 & 0 \\
$5-30$ & 1 & $<1$ & 1 & $1-4$ & 1 & 3 \\
$1-4$ & 2 & $1-4$ & 2 & $5-30$ & 3 & 3 \\
$<1$ & 3 & $5-30$ & 3 & 30 or $>$ & 4 & 8 \\
0 & 4 & 30 or $>$ & 4 & & \\
\hline
\end{tabular}

(b)

\begin{tabular}{lcc}
\hline & ${ }^{*}$ Interpretation of Nugent Score & And \\
If $\mathrm{N}$ score is & & Normal \\
$0-3$ & Clue cells not present & Intermediate \\
$4-6$ & Clue cells are present & Bacterial vaginosis \\
$4-6$ & & \\
\hline
\end{tabular}

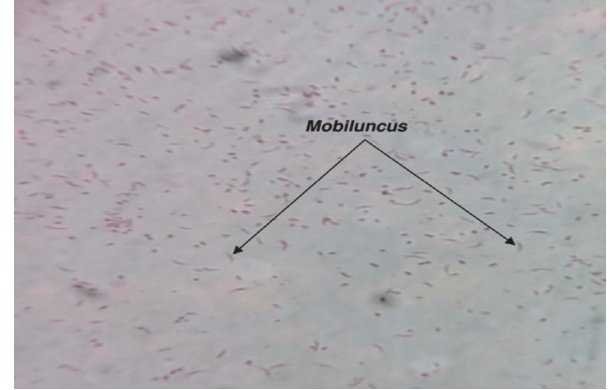

FIGURE 3: Direct Gram stain of high vaginal swab showing Gram negative curved rods-Mobiluncus.

\section{Results}

Upon examination of 160 nonpregnant women with symptomatic vaginal discharge, the overall prevalence of BV was $24.4 \%$ based on Nugent's scoring system.

The highest number of BV cases was seen among 30-40 years' age group $(8.8 \%)$ and least BV cases were seen in patients with age group of $10-20$ and $50-60$ years $(1.3 \%)$. Unmarried women were more prone to BV, that is, (100\%), followed by married women (24.2\%). Illiterate women were highest with $21.9 \%$ of total respondents. The prevalence of BV was high among farmers (38.9\%) and low in those who were involved in business $(14.7 \%)$. Higher rate of BV was seen among other ethnicity (57.1\%) followed by Dalit (50\%), Brahmin (25\%), Janajati (22.7\%), and Chhetri (19.4\%) among all respondents. Hence, women of age group 30-40 years, unmarried, illiterate, farmers, and belonging to other ethnic groups were more prone to BV (Table 2). However, the result was not statistically significant at $\alpha=0.05$.

The prevalence of BV was found higher in daily smokers (30\%) while low rate was reported among occasional smokers (0\%). Daily alcohol users had the highest prevalence of BV of $38.5 \%$ while the least prevalence of $24 \%$ was recorded among those who never drank alcohol and $16.7 \%$ were occasional alcohol users. BV was seen very high among nonvegetarians with $25.2 \%$ whereas it was only $15.4 \%$ among vegetarians. The risk of $\mathrm{BV}$ was higher among those who used condom daily $(42.9 \%)$ than those who used condoms sometimes $(29.2 \%)$. Women having daily douching habit were more likely to have BV (32.1\%) than in women with occasional douching habit $(23.7 \%)$ and the difference was significant $(P=0.015)$ (Table 3).

The highest prevalence of BV was found among women whose partner had undergone tubectomy (50\%) and least prevalence was found among OC pills users (9.1\%) (Table 4).

In terms of consistency of abnormal vaginal discharge among BV cases, occurrence of the thin discharge had the highest prevalence $(39.8 \%)$ while the least was among women with normal discharge (4.9\%). Foul discharge was reported in $(29.9 \%)$ of patients while nonfoul discharge was found in $(14.3 \%)$ of patients. Excess discharge was observed in patients with BV (30\%) while scanty discharge was observed in $(18.7 \%)$. Women with BV were found to be associated with consistency, odor, and amount of vaginal discharge $(P<$ 0.05) (Table 5).

A total of 99 bacteria belonging to 14 different species were isolated from vaginal samples, which are tabulated in Table 6. Among the isolates, 41 (32\%) were Gram negative and 58 (45.3\%) were Gram positive. Other isolates including yeasts and parasites were 29 (22.7\%). Of the Gram negative bacteria, Pseudomonas spp., E.coli, and Acinetobacter spp. were predominant. Lactobacillus spp. were the dominant Gram positive bacteria found in vaginal samples.

\section{Discussion}

Globally, BV is a common genital problem among women seeking gynaecological care. The prevalence rate of BV was found to be $24.4 \%$ by Nugent's method. Modak et al. [19] in India reported a similar result, providing a prevalence rate of $24 \%$. Higher prevalence rates of BV than those in the present study were also reported by Gad et al. [20] in Egypt (33\%). 
TABLE 2: Sociodemographic characteristics of sample distribution.

\begin{tabular}{|c|c|c|c|c|}
\hline & & Bacterial vagino & & $P$ value \\
\hline & Number (160) & Positive number (\%) & Negative number (\%) & 1 varue \\
\hline Age & & & & \\
\hline $10-20$ & 7 & $2(1.3)$ & $5(3.1)$ & \\
\hline $20-30$ & 48 & $13(8.1)$ & $35(21.8)$ & \\
\hline $30-40$ & 75 & $14(8.8)$ & $61(38.1)$ & 0.50 \\
\hline $40-50$ & 22 & $8(5)$ & $14(8.8)$ & \\
\hline $50-60$ & 8 & $2(1.3)$ & $6(3.7)$ & \\
\hline Marital status & & & & \\
\hline Unmarried & 1 & $1(100)$ & $0(0)$ & \\
\hline Married & 153 & $37(24.2)$ & $116(75.8)$ & 0.32 \\
\hline Widowed & 5 & $1(20)$ & $4(80)$ & 0.02 \\
\hline Divorced/separated & 1 & $0(0)$ & $1(100)$ & \\
\hline Education & & & & \\
\hline Illiterate & 55 & $16(29.1)$ & $39(70.9)$ & \\
\hline Just literate & 7 & $1(14.3)$ & $6(85.7)$ & \\
\hline Primary level & 27 & $7(25.9)$ & $20(74.1)$ & \\
\hline Secondary & 41 & $8(19.5)$ & $33(80.5)$ & 0.93 \\
\hline Higher S. & 15 & $3(20)$ & $12(80)$ & \\
\hline Bachelors & 11 & $3(27.3)$ & $8(72.7)$ & \\
\hline Master & 4 & $1(25)$ & $3(75)$ & \\
\hline Occupation & & & & \\
\hline Civil servants & 23 & $7(30.4)$ & $16(69.6)$ & \\
\hline Farmers & 18 & $7(38.9)$ & $11(61.1)$ & \\
\hline Business & 34 & $5(14.7)$ & $29(85.3)$ & 0.36 \\
\hline Housewife & 81 & $19(23.5)$ & $62(76.5)$ & \\
\hline Student & 4 & $1(25)$ & $3(75)$ & \\
\hline Ethnicity & & & & \\
\hline Brahmin & 40 & $10(25)$ & $30(75)$ & \\
\hline Chhetri & 36 & $7(19.4)$ & $29(80.6)$ & \\
\hline Janajati & 75 & $17(22.7)$ & $58(77.3)$ & 0.24 \\
\hline Dalit & 2 & $1(50)$ & $1(50)$ & \\
\hline Others $^{\dagger}$ & 7 & $4(57.1)$ & $3(42.9)$ & \\
\hline
\end{tabular}

${ }^{\dagger}$ Include Madhesi, Marwari, Bangali, Jain, and Punjabi/Sikh.

The variation in the findings might be due to population size, methods of analysis, geographic distribution, and socioeconomic and behavioral differences in the studied population.

The present study revealed that the prevalence of BV was high among women of age group 30-40 years $(8.8 \%)$ and least for 10-20 and 50-60 years' age groups (1.3\%). However, the difference between them was not statistically significant. Bhattarai [6] in Nepal observed the highest prevalence of BV among the age group of 31-40 years (60.16\%) and least among those below 20 years of age and 51-60 age group $(33.33 \%)$ which was similar to the above study. Also, Garba et al. [21] in Nigeria found BV to be most prevalent among $26-30$ age group (35.8\%) and least in $>40$ age (10.5\%). The highest prevalence in the age group 30-40 years might be due to the age being the most reproductively active age group and high sexual exposure at this age.

According to this study, unmarried women were at higher risk (100\% tested positive) compared to married women
(24.2\%). The finding of the study is contradicted by Gad et al. [20] in Egypt. However, several studies have documented the occurrence of BV in sexually inactive females or virgins $[22,23]$. This provides evidence that sexual activity is not a prerequisite for BV. The change in lifestyle, improper perineal care, food habits, tight clothing, lack of attention towards menstrual hygiene, and sedentary factor might be the reasons for the acquisition of BV in unmarried women.

Similarly, illiterate women had the highest BV prevalence of $29.1 \%$ which differs from Ibrahim et al. [24] who recorded the highest prevalence of $54 \%$ in those with primary education in Nigeria. The low economic status, lack of education, lack of a female consultant at the health service center, hesitance to approach medical service, and sociocultural structure might be the cause of higher prevalence of $\mathrm{BV}$ among less educated women.

In the study, higher rate of BV was seen among farmers which is similar to the finding of a study undertaken by 
TABLE 3: Distribution of cases according to behavior characteristics.

\begin{tabular}{lccc}
\hline & & Bacterial vaginosis & Negative number (\%) \\
\hline Smoking & Number (160) & $36(25.71)$ & $104(74.29)$ \\
Never & 140 & $3(30)$ & $7(70)$ \\
Daily & 10 & $0(0)$ & $10(100)$ \\
Occasional & 10 & & $98(76)$ \\
Alcohol intake & 129 & $31(24)$ & $8(61.5)$ \\
Never & 13 & $5(38.5)$ & $15(83.3)$ \\
Daily & 18 & $3(16.7)$ & $11(84.6)$ \\
Occasional & 13 & & $110(74.8)$ \\
Diet & 147 & $2(15.4)$ & 0.17 \\
Veg & & $37(25.2)$ & $100(77.5)$ \\
Nonveg & 129 & & $4(57.1)$ \\
Condom use & 7 & $29(22.5)$ & $17(70.8)$ \\
Never & 24 & $3(42.9)$ & 0.43 \\
Daily & & $7(29.2)$ & $35(92.1)$ \\
Sometime & 38 & $3(7.9)$ & $57(67.9)$ \\
Douching & 84 & $27(32.1)$ & $29(76.3)$ \\
Never & 38 & $9(23.7)$ & 0.39 \\
Daily & & & \\
Sometime & & &
\end{tabular}

${ }^{*} P$ value $<0.05$ was considered statistically significant.

TABLE 4: Distribution of BV using different contraceptives.

\begin{tabular}{lccc}
\hline Contraceptive types & Number $N(160)$ & $\begin{array}{c}\text { Bacterial vaginosis } \\
\text { Positive number (\%) }\end{array}$ & Negative number (\%) \\
\hline Nonanatomical sites & 11 & $1(9.1)$ & $10(90.9)$ \\
OC pills & 17 & $3(17.6)$ & $14(82.4)$ \\
Depo-Provera & 5 & $1(20)$ & $4(80)$ \\
Implant & & & $22(73.3)$ \\
Anatomical sites & 30 & $8(26.7)$ & $7(70)$ \\
Barrier method & 10 & $3(30)$ & $3(50)$ \\
IUCD & 6 & $3(50)$ & $7(64)$ \\
Vasectomy (male) & 11 & $4(36)$ & $54(78)$ \\
Tubectomy (female) & 70 & $16(22)$ & 0.2 \\
Nonusers & & & \\
\hline
\end{tabular}

Garba et al. [21] in Nigeria who reported the highest prevalent BV (52.6\%) in farmers. Again, the magnitude of BV was higher among women of other ethnicity, which is different from a survey conducted in Nepal by Manandhar et al. [25] that reported the highest prevalence of BV in Dalits. A combination of environmental, contextual and institutional factors, and chronic stress may contribute to this disparity [15].

Moreover, the study revealed that daily smokers were more prone to $\mathrm{BV}$ than those who never smoke but the difference between them was not significant $(P>0.05)$ which is contrary to the results of a study carried out by Manandhar et al. [25] in Nepal. Risk of BV increases as the number of cigarettes smoked per day increases. Various chemical constituents of cigarette smoke alter the vaginal microflora or may act by depleting Langerhans cells in cervical epithelium leading to local immunosuppression, thus causing BV [26]. The study showed daily alcohol users had a higher rate of BV $(38.5 \%)$ than those with an occasional consumption of alcohol but this association was not significant. However, the finding is consistent with the report of Hellberg et al. [27] in Sweden which stated that alcohol use was not significantly associated with BV. Smoking cigarettes and alcohol intake causes depletion of hydrogen peroxide-producing lactobacilli, therefore increasing the risk of BV. This study showed nonvegetarians had high BV occurrence (25.2\%) than vegetarians $(15.7 \%)$ which was statistically insignificant $(P>$ 0.05). The finding is similar to the finding by Manandhar et al. [25] in Nepal. High fat intake, particularly saturated fat, may increase vaginal $\mathrm{pH}$, thereby increasing the risk of $\mathrm{BV}$ [28]. 
TABLE 5: Sample distribution on the basis of symptoms.

\begin{tabular}{|c|c|c|c|c|}
\hline \multirow{2}{*}{ Vaginal symptoms } & \multicolumn{3}{|c|}{ Bacterial vaginosis } & \multirow{2}{*}{$P$ value } \\
\hline & Number $N(160)$ & Positive number (\%) & Negative number (\%) & \\
\hline \multicolumn{5}{|l|}{ Discharge } \\
\hline Normal & 61 & $3(4.9)$ & $58(95.1)$ & \multirow{3}{*}{$0.0001^{*}$} \\
\hline Thin & 83 & $33(39.8)$ & $50(60.2)$ & \\
\hline Thick & 16 & $3(18.8)$ & $13(81.2)$ & \\
\hline \multicolumn{5}{|l|}{ Odor } \\
\hline Foul & 104 & $31(29.9)$ & $73(70.1)$ & \multirow{2}{*}{$0.02^{*}$} \\
\hline Nonfoul & 56 & $8(14.3)$ & $48(85.7)$ & \\
\hline \multicolumn{5}{|l|}{ Color } \\
\hline White & 126 & $34(27)$ & $92(73)$ & \multirow{2}{*}{0.13} \\
\hline Grey & 34 & $5(14.7)$ & $29(85.3)$ & \\
\hline \multicolumn{5}{|l|}{ Amount } \\
\hline Excess & 80 & $24(30)$ & $56(70)$ & \multirow{2}{*}{$0.09^{*}$} \\
\hline Scanty & 80 & $15(18.7)$ & $65(81.3)$ & \\
\hline \multicolumn{5}{|l|}{ Abdominal pain } \\
\hline Yes & 83 & $22(26.6)$ & $61(73.4)$ & \multirow{2}{*}{0.51} \\
\hline No & 77 & $17(22.1)$ & $60(77.9)$ & \\
\hline \multicolumn{5}{|l|}{ Itching } \\
\hline Yes & 56 & $13(23.2)$ & $43(76.8)$ & \multirow{2}{*}{0.80} \\
\hline No & 104 & $26(25)$ & $78(75)$ & \\
\hline
\end{tabular}

${ }^{*} P$ value $<0.05$ was considered statistically significant.

TABLE 6: Prevalence of microorganisms isolated from vaginal swabs.

\begin{tabular}{lc}
\hline Microorganisms & Number (\%) \\
\hline Gram negative: & \\
Escherichia coli & $8(6.3)$ \\
Klebsiella spp. & $4(3.1)$ \\
Proteus vulgaris & $1(0.8)$ \\
Proteus mirabilis & $4(3.1)$ \\
Pseudomonas spp. & $10(7.8)$ \\
Neisseria gonorrhoeae & $4(3.1)$ \\
Acinetobacter spp. & $8(6.3)$ \\
Citrobacter koseri & $1(0.8)$ \\
Enterobacter spp. & $1(0.8)$ \\
Gram-positive: & \\
Streptococcus agalactiae & $7(5.5)$ \\
Staphylococcus aureus & $7(5.5)$ \\
CoNS & $4(3.1)$ \\
Enterococcus spp. & $5(3.9)$ \\
Lactobacillus spp. & $35(27.3)$ \\
Others: (yeasts and parasite) & \\
Yeast: & \\
Candida albicans & \\
Candida spp. & $3(2.3)$ \\
Trichomonas vaginalis & $12(9.4)$ \\
\hline
\end{tabular}

In this study, the prevalence of BV was higher among women whose partners were daily condom users than those who were not. However, no significant association was found.
The findings are more consistent with the study conducted by Mascarenhas et al. [4] in Brazil who reported no association between $\mathrm{BV}$ and condom use. One possible explanation for this is that condoms may cause irritation giving the bacteria a way to get into the vagina and increase risk of having BV.

It was observed that $32.1 \%$ of the BV positive cases were among women having a daily vaginal douching habit and $23.7 \%$ were found positive on those women having the habit of douching sometimes. This confirms that vaginal douches represent a risk factor for BV acquisition. A previous study also suggested a strong association between vaginal douching and BV $[3,19]$. The lack of effort and awareness on the health hazards of this incorrect practice might be regarded as the cause of higher possibilities of BV among women having vaginal douches habit.

The study also clarifies that the chance of getting BV increases in those women who have used contraceptives on anatomical sites than those who had not. So, use of contraceptives on anatomical sites may cause imbalance in vagina flora and leads to BV. Lowest rate of BV was seen among women using OC pills (9.1\%). The estrogen increases the glycogen content of vaginal epithelial cell activity, in turn inhibiting the in vitro growth of certain bacteria, which may result in low risk for BV [16]. Similarly, the study also agrees with Thulkar et al. [29] in India who reported protective effects of hormonal contraceptives against BV.

In this investigation, consistency, odor, and amount of vaginal discharge were found to be statistically significant with $\mathrm{BV}(P<0.05)$. This finding corresponds with previous study conducted by Garba et al. [21] in Nigeria. White colored vaginal discharge had the highest prevalence than 
gray colored discharge and was found not to be associated with diagnosis of BV. There is no specific color of vaginal discharges for the diagnosis of BV; experts varied in opinion but it is important to know that women with BV present abnormal vaginal discharges and the vaginal discharges differ in the consistency, Garba et al. [21]. Abdominal pain and itching symptoms were found in $26.6 \%$ and $23.2 \%$, respectively, which was consistent with the result reported by Nzomo et al. [30] in Kenya. This study registered no significant relationship between abdominal pain, itching, and BV.

Of the 128 isolates, 35 isolates belonged to Lactobacillus spp. and 93 isolates were of opportunistic pathogens. Lactobacillus spp. was isolated as the most predominant species and accounted for $27.3 \%$ of the total bacterial isolates. Higher prevalence of Lactobacillus in this study also resembles the study done by Razzak et al. [31] in Iraq and Larsen and Monif [32] in Omaha. Therefore, Lactobacillus plays a protective and probiotic role in treating and preventing vaginal infection by producing antagonizing compounds and is regarded as safe for human [31].

The second common pathogen was Pseudomonas spp., accounting for $7.8 \% \mathrm{BV}$ cases, followed by many other Gram negative bacteria, namely, E. coli, Acinetobacter spp., Proteus spp., Klebsiella spp., N. gonorrhoeae, C. koseri, and Enterobacter spp. But, the findings of the study contradict with the studies undertaken by Razzak et al. [31] in Iraq, Marrazzo et al. [33] in Seattle, and Larsen and Monif [32] in Omaha. Pseudomonas spp. is potentially opportunistic bacteria within the vagina and may become increasingly prevalent upon minor alterations of the vaginal environment. It is considered as primary pathogen in compromised hosts, hospitalized patients, and complicated urinary tract infection [34]. Collectively, Mumtaz et al. [35] suggest that the presence of members of faecal flora in the vagina is attributed to unhygienic bowel practices.

The most common Gram positive cocci were Staphylococcus aureus and Streptococcus agalactiae in the study. The incidence was found to be $5.5 \%$ of total bacterial isolates each. This is consistent with the findings of Maghsoudi et al. [36] in Pakistan, Tiyyagura et al. [37] in India, and AlMousawi et al. [38] in Iraq. The vaginal mucosa colonized by S. aureus predisposes them to Toxic Shock Syndrome (TSS). The second most prevalent organism among Gram positive cocci were CoNS and Enterococcus spp. accounting for 3.1\% and $3.9 \%$, respectively. The finding is similar to the study conducted by Masood et al. [39] in Pakistan. CoNS is also a common vaginal colonizer. It continues to be the most important bacterial cause of bacterial sepsis and meningitis in newborns. Enterococci are an opportunistic pathogen and can cause infection when the immune system is impaired.

Regarding the frequency of yeasts and parasites isolated from patients, Candida albicans (2.3\%) and other Candida spp. $(9.4 \%)$ were reported. The finding is inconsistent with the reported prevalence of candidal infection by Al-Muk and Hasony [40] in Iraq and similar to Maghsoudi et al. [36]. T. vaginalis was observed in 14 cases $(10.9 \%)$ by wet mount preparation. These are nearly similar to the study reported by Begum et al. [5] in Dhaka (8\%).
The levels of these various organisms vary in each woman [41]. The results showed that the presence of lactobacilli together with other opportunistic pathogens may be due to several factors like effects of antibiotics, type of incubation (as some Lactobacillus spp. are unable to produce some defense factors under anaerobic incubation), and antagonism among lactobacilli species to maintain dominance [31]. Also, some studies have reported that there can be chance of overlap of $\mathrm{BV}$ and aerobic vaginitis, leading to a mixed condition, but whether one condition can evolve into the other has not yet been determined [42].

\section{Conclusion}

The study suggests that using contraceptives on anatomical sites may confer a higher risk for BV. Some factors, especially vaginal douching, may increase the risk of BV. Lactobacillus spp. were the predominant isolates found in the vaginal sample followed by a number of Enterobacteriaceae members and Gram positive bacteria. This finding suggests that the colonization of facultative anaerobes is also more likely a consequence in vaginal ecology. Limited studies on BV have been performed in Nepal. So, similar studies must be carried out in order to improve the health status of women, thereby preventing the risk posed towards BV.

\section{Data Availability}

All data generated or analyzed during the current study are included in this published article.

\section{Additional Points}

Limitation of the Study. Most of the anaerobes associated with BV are fastidious and require selective enriched media, and sometimes they are not easy to identify using traditional biochemical tests. In addition, a number of organisms that seemed associated with BV are uncultivable, for example, species of Eggerthella, Megasphaera, and BVABs members of Clostridiales. Also, it was demonstrated that, in women of reproductive age group, anaerobic bacteria outnumbered aerobic bacteria; however, the latter appeared to be more abundant with advancing age, onset of sexual activity, and parity of women.

\section{Ethical Approval}

Ethical approval was obtained from the Institutional Review Committee (IRC), KIST Medical College Teaching Hospital, Lalitpur, Gwarko, Nepal, on 2nd of November, 2014.

\section{Consent}

Verbal consent was obtained from all participants at recruitment.

\section{Conflicts of Interest}

The authors declare that they have no conflicts of interest. 


\section{Authors' Contributions}

Laboratory investigations were performed by Eliza Ranjit and Bijendra Raj Raghubanshi. Eliza Ranjit designed the study and analyzed the data. Eliza Ranjit and Pramila Parajuli contributed to data interpretation. Eliza Ranjit drafted the manuscript. All the authors have read and approved the final manuscript.

\section{Acknowledgments}

The authors would like to thank Dr. Balman Singh Karki for helpful discussions. Special thanks also goes to Mr. Sudhakar Pant for his full support. They are personally grateful to $\mathrm{Mr}$. Narad Pandey for contributing materials and reagents. They are especially grateful to Dr. Yogesh Ranjit and Professor Juju G. Ranjit for data analysis and interpretation. Funding was provided for this study by KIST Medical College and Teaching Hospital.

\section{References}

[1] B. A. Forbes, D. F. Sahm, A. S. Weissfeld, and W. R. Bailey, Bailey and Scotts Diagnostic Microbiology, Elsevier, Mobsy, Louis, MO, USA, 12th edition, 2007.

[2] J. M. Bohbot, P. Sednaoui, F. Verriere, and B. NystatinNeomycin-Polymyxin, "Nystatin-Neomycin-Polymyxin B Combination: Efficacy and Tolerance as 1st-Line Local Treatment of Infectious Vaginitis," Open Journal of Obstetrics Gynecology, vol. 4, pp. 445-454, 2014.

[3] R. Elgantri, A. Mohamed, and F. Ibrahim, "Diagnosis of Bacterial Vaginosis by Amsel Criteria and Gram Stain Method," Sebha MedicalJournal, vol. 9, no. 1, pp. 20-27, 2010.

[4] R. E. M. Mascarenhas, M. S. C. Machado, B. F. B. E. Costa Silva et al., "Prevalence and Risk Factors for Bacterial Vaginosis and Other Vulvovaginitis in a population of Sexually Active Adolescents from Salvador," in Infectious Disease of Obstetrics Gynecology, p. 6, Brazil, Bahia, 2012.

[5] N. Begum, N. Muazzam, S. Shamsuzzaman, A. Chowdhury, A. Rashid, and D. Islam, "Diagnosis of Bacterial Vaginosis by Acridine Orange Staining and its Comparison to Conventional Methods and Association of Gardnerella vaginalis with Bacterial Vaginosis," Bangladesh Journal of Medical Microbiology, vol. 4, no. 1, 2010.

[6] S. Bhattarai, Prevalence of common types of vaginitis (Bacterial vaginosis, Candidiasis, Trichomonasis) and their correlation with urinary tract infection among women visiting [Dissertation, thesis], 2012, submitted to.

[7] S. Cauci, F. Scrimin, S. Driussi et al., "Specific immune response against Gardnerella vaginalis hemolysin in patients with bacterial vaginosis," American Journal of Obstetrics \& Gynecology, vol. 175, no. 6, pp. 1601-1605, 1996.

[8] R. S. Jesus, L. N. Calil, R. D. Reis, and A. M. Fuentefria, "Bacterial Vaginosis: Some Aspects for Clinical Practice," Revista Panamericana De Infectologia, vol. 13, no. 4, pp. 49-56, 2011.

[9] C. H. Livengood, "Bacterial vaginosis: an overview for 2009," Revisionin Obstetrics Gynecology, vol. 2, no. 1, pp. 28-37, 2009.

[10] R. W. Hyman, M. Fukushima, L. Diamond, J. Kumm, L. C. Giudice, and R. W. Davis, "Microbes on the human vaginal epithelium," Proceedings of the National Acadamy of Sciences of the United States of America, vol. 102, no. 22, pp. 7952-7957, 2005.

[11] R. Martin, N. Soberqn, F. Vázquez, and J. E. Suárez, "Vaginal microbiota: Composition, protective role, associated pathologies, and therapeutic perspectives," Enfermedades Infecciosas y Microbiología Clínica, vol. 26, no. 3, pp. 160-167, 2008.

[12] D. S. C. Filho, C. G. Diniz, and V. L. Silva, "Bacterial vaginosis: clinical, epidemiological and microbiological features," HURevista Juiz de Fora, vol. 36, no. 3, pp. 223-230, 2010.

[13] S. Ahmed, T. Lutalo, M. Wawer et al., "HIV incidence and sexually transmitted disease prevalence associated with condom use: A population study in Rakai, Uganda," AIDS, vol. 15, no. 16, pp. 2171-2179, 2001.

[14] H. Verstraelen, R. Verhelst, M. Vaneechoutte, and M. Temmerman, "The epidemiology of bacterial vaginosis in relation to sexual behaviour," BMC Infectious Diseases, vol. 10, article 81, 2010.

[15] J. Brumley, "Testing a Model of Bacterial Vaginosis among Black Women,” Doctor of Philosophy Dissertations, pp. 44-52, 2012, submitted to.

[16] H. O. Singh, A. Singh, T. N. Dhole, and S. Nain, "Factor Associated to Bacterial Vaginosis in Non-pregnant Women of North Indian Population," Journal of Biotechnology Biomaterials, vol. 5, p. 195, 2015.

[17] L. A. Vodstrcil, J. S. Hocking, M. Law et al., "Hormonal Contraception Is Associated with a Reduced Risk of Bacterial Vaginosis: A Systematic Review and Meta-Analysis," PLoS ONE, vol. 8, no. 9, Article ID e73055, 2013.

[18] R. P. Nugent, M. A. Krohn, and S. L. Hillier, "Reliability of diagnosing bacterial vaginosis is improved by a standardized method of gram stain interpretation," Journal of Clinical Microbiology, vol. 29, no. 2, pp. 297-301, 1991.

[19] T. Modak, P. Arora, C. Agnes et al., "Diagnosis of bacterial vaginosis in cases of abnormal vaginal discharge: comparison of clinical and microbiological criteria," The Journal of Infection in Developing Countries, vol. 5, no. 05, 2011.

[20] G. F. Gad, A. R. El-Adawy, M. S. Mohammed, A. F. Ahmed, and H. A. Mohamed, "Evaluation of different diagnostic methods of bacterial vaginosis," IOSR Journal of Dental and Medical Sciences, vol. 13, no. 1, pp. 15-23, 2014.

[21] D. J. Garba, S. S. Zabaze, Vem, S. Tabitha, G. James, and K. Makshwar, "Microbiological Diagnosis of Bacterial Vaginosis in Pregnant Women in a Resource Limited Setting in North Central Nigeria," American Journal of Life Sciences, vol. 2, no. 6, p. 356, 2014.

[22] M. Vaca, I. Guadalupe, S. Erazo et al., "High prevalence of bacterial vaginosis in adolescent girls in a tropical area of Ecuador," BJOG: An International Journal of Obstetrics \& Gynaecology, vol. 117, no. 2, pp. 225-228, 2010.

[23] S. Yen, M.-A. Shafer, J. Moncada, C. J. Campbell, S. D. Flinn, and C. B. Boyer, "Bacterial vaginosis in sexually experienced and non-sexually experienced young women entering the military," Obstetrics \& Gynecology, vol. 102, no. 5, pp. 927-933, 2003.

[24] S. M. Ibrahim, M. Bukar, G. B. Galadima, B. M. Audu, and H. A. Ibrahim, "Prevalence of bacterial vaginosis in pregnant women in Maiduguri, North-Eastern Nigeria," Nigerian Journal of Clinical Practice, vol. 17, no. 2, pp. 154-158, 2014.

[25] R. Manandhar, J. Sharma, B. Pokharel, B. Shrestha, and N. Pradhan, "Bacterial vaginosis in Tribhuvan University Teaching 
Hospital," Journal of Institute of Medicine, vol. 27, no. 2, pp. 2-5, 2007.

[26] S. Smart, A. Singal, and A. Mindel, "Social and sexual risk factors for bacterial vaginosis," Sexually Transmitted Infections, vol. 80, no. 1, pp. 58-62, 2004.

[27] D. Hellberg, S. Nilsson, and P.-A. Mårdh, "The diagnosis of bacterial vaginosis and vaginal flora changes," Archives of Gynecology and Obstetrics, vol. 265, no. 1, pp. 11-15, 2001.

[28] Y. H. Neggers, T. R. Nansel, W. W. Andrews et al., "Dietary intake of selected nutrients affects bacterial vaginosis in women," Journal of Nutrition, vol. 137, no. 9, pp. 2128-2133, 2007.

[29] J. Thulkar, A. Kriplani, N. Agarwal, and S. Vishnubhatla, "Aetiology \& risk factors of recurrent vaginitis \& its association with various contraceptive methods," Indian Journal of Medical Research, vol. 131, no. 1, pp. 83-87, 2010.

[30] J. Nzomo, P. Waiyaki, and R. Waihenya, "Bacterial Vaginosis and Correlates in Women of Reproductive Age in Thika, Kenya," Advances in Microbiology, vol. 03, no. 03, pp. 249-254, 2013.

[31] M. S. A. Razzak, A. H. Al-Charrakh, and B. H. Al-Greitty, "Relationship between lactobacilli and opportunistic bacterial pathogens associated with vaginitis," North American Journal of Medical Sciences, vol. 3, no. 4, pp. 185-192, 2011.

[32] B. Larsen and G. R. G. Monif, "Understanding the bacterial flora of the female genital tract," Clinical Infectious Diseases, vol. 32, no. 4, pp. e69-e77, 2001.

[33] J. M. Marrazzo, K. K. Thomas, T. L. Fiedler, K. Ringwood, and D. N. Fredricks, "Relationship of specific vaginal bacteria and bacterial vaginosis treatment failure in women who have sex with women," Annals of Internal Medicine, vol. 149, no. 1, pp. 20-W12, 2008.

[34] N. Puri, B. Jha, B. Lekhak, and RC. Adhikari, Study on the incidence of urinary tract infection in diabetic patients and the prevalence of multidrug resistant strains among the bacterial pathogens isolates [Dissertation, thesis], A Dissertation Submitted to the, Kathmandu, Nepal, 2006.

[35] S. Mumtaz, M. Ahmad, I. Aftab, N. Akhtar, M. ul Hassan, and A. Hamid, "Aerobic vaginal pathogens and their sensitivity pattern," Journal of Ayub Medical College, vol. 20, no. 1, pp. 113$117,2008$.

[36] R. Maghsoudi, A. Danesh, N. Kabiri, M. Setorki, and M. Doudi, "Prevalence of the genital tract bacterial infections after vaginal reconstructive surgery," Pakistan Journal of Biological Sciences, vol. 17, no. 9, pp. 1058-1063, 2014.

[37] S. Tiyyagura, M. Taranikanti, S. Ala, and D. R. Mathur, "Bacterial vaginosis in indian women in the reproductive age group," International Journal of Biomedical Research, vol. 3, no. 8, 2012.

[38] J. K. N. Al-Mousawi, H. R. Tarish, and M. M. K. Al-Saadi, "Microbiology study of bacterial vaginosis among pregnant women in Al-Diwaniya city," Medical JournalofBasrah University, vol. 24, no. 1-2, pp. 30-37, 2006.

[39] S. N. Masood, S. Mumtaz, and M. Jahan, "Pattern of normal flora in healthy married non -pregnant women," Pakistan Journal Of Surgery, vol. 25, no. 2, pp. 128-131, 2009.

[40] J. M. Al-Muk and H. J. Hasony, "Isolation of Gardnerella vaginalis from pregnant women with bacterial vaginosis in Basrah, Iraq," Bahrain Medical Bulletin, vol. 23, no. 3, pp. 124126, 2001.

[41] D. Schwab, Vaginitis- Molecular Testing To Address Diagnostic Challenges, ClinicalEducation Center, 2014, http://education .questdiagnostics.com/insights/72.
[42] G. G. G. Donders, A. Vereecken, E. Bosmans, A. Dekeersmaecker, G. Salembier, and B. Spitz, "Definition of a type of abnormal vaginal flora that is distinct from bacterial vaginosis: Aerobic vaginitis," BJOG: An International Journal of Obstetrics \& Gynaecology, vol. 109, no. 1, pp. 34-43, 2002. 


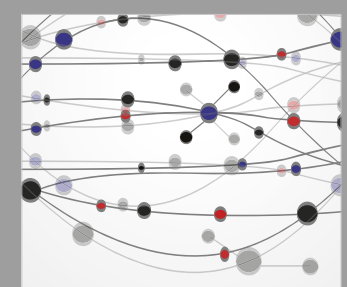

The Scientific World Journal
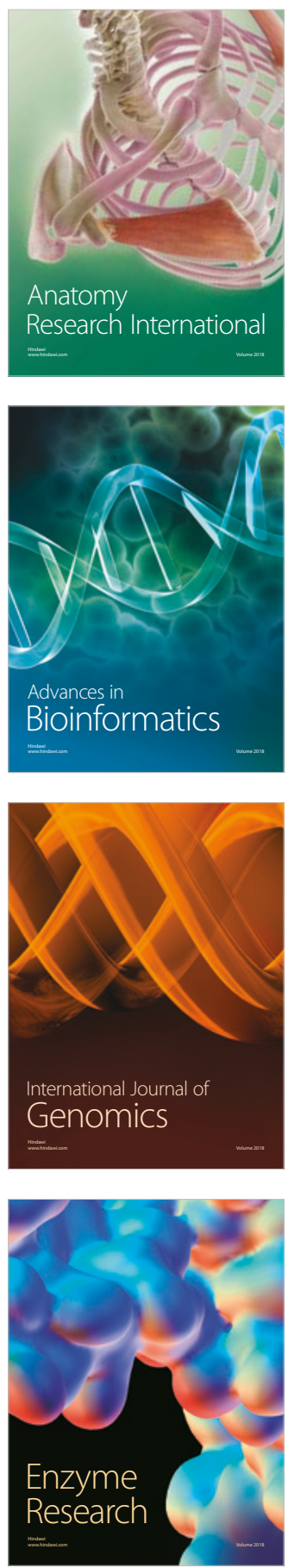
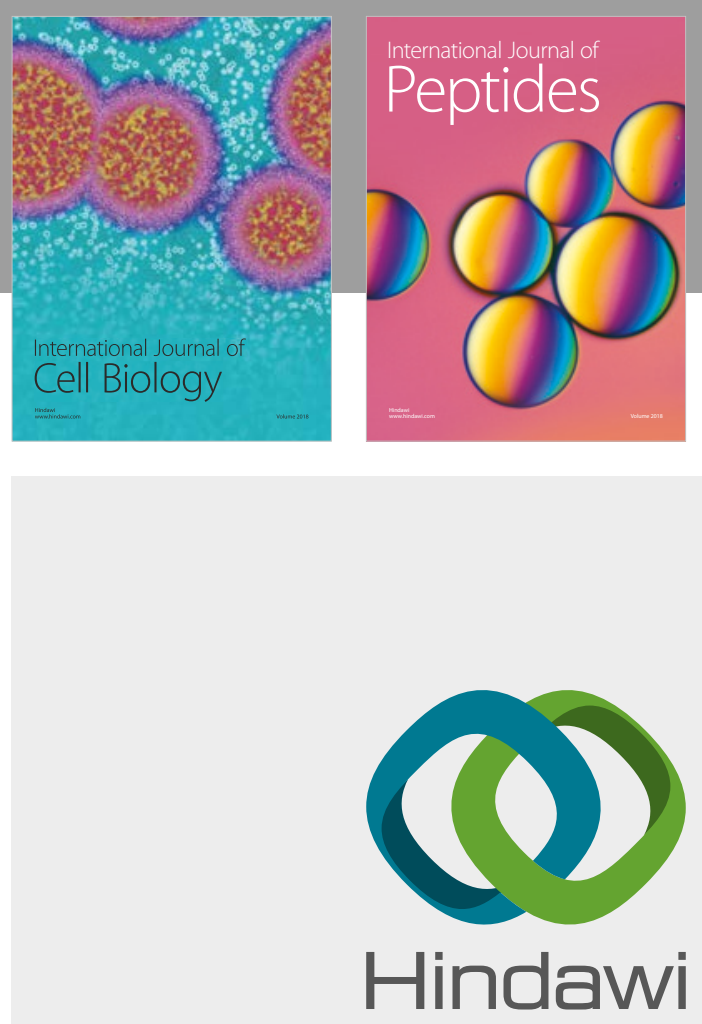

Submit your manuscripts at

www.hindawi.com
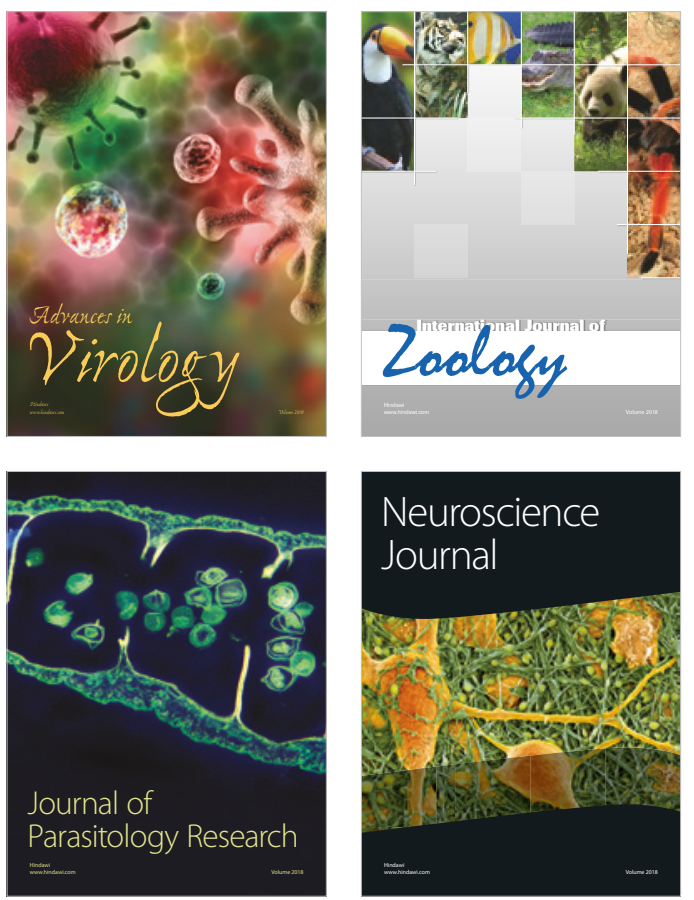
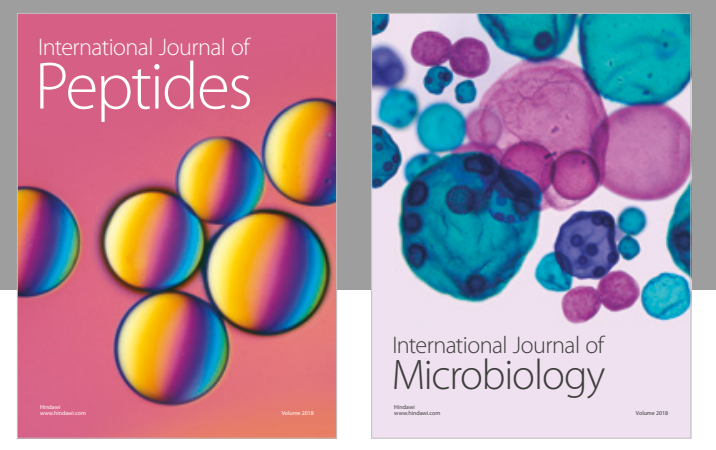

nternational Journal of Microbiology
Journal of
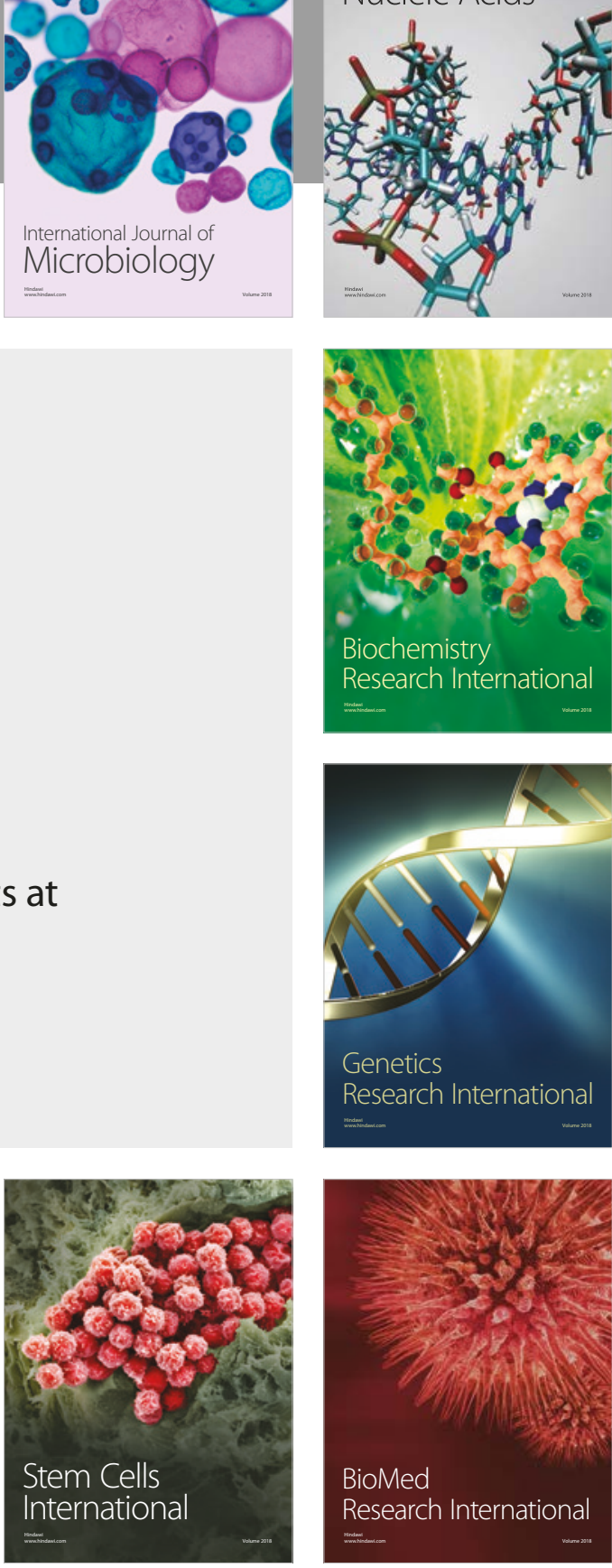
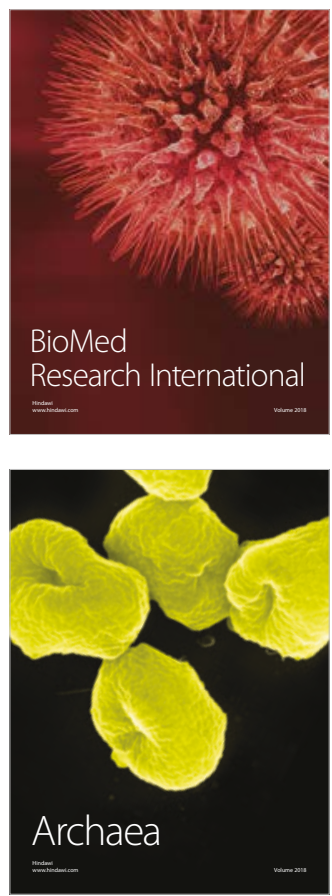